\title{
Cooperação universidade-empresa: um estudo do projeto UNISINOS - HT Micron para o desenvolvimento de capacidade absortiva na área de semicondutores
}

\section{University-industry cooperation: a study of the UNISINOS - HT Micron project for developing absorptive capacity in the area of semiconductors}

\author{
Sabrina Rossi de Oliveira ${ }^{1}$ \\ Alsones Balestrin ${ }^{1}$
}

\begin{abstract}
Resumo: A capacidade de uma organização identificar, assimilar e aplicar conhecimento do ambiente externo é estudada no campo das teorias organizacionais sob a temática denominada "capacidade absortiva". A corrente principal da literatura tem considerado a capacidade absortiva como uma habilidade dependente da trajetória da organização, o que a torna difícil de ser desenvolvida em um espaço relativamente curto de tempo. Entretanto, existem pesquisas que revelam que, dependendo do tipo de conhecimento que se pretende adquirir, a capacidade absortiva poderá ser desenvolvida de maneira mais específica. Em face dessa problemática, o presente artigo busca investigar o desenvolvimento da capacidade absortiva de uma universidade brasileira, diante do desafio de atuar em um projeto colaborativo junto à indústria de semicondutores. Para a pesquisa empírica adotou-se a estratégia de estudo de caso único, por meio de entrevistas em profundidade, utilizando o projeto UNISINOS - HT Micron com unidade de análise. As evidências sugerem que a capacidade absortiva foi aperfeiçoada por meio de ações que influenciaram a base de conhecimento, a capacitação de recursos humanos, o desenvolvimento da estrutura organizacional e o estabelecimento de relações interorganizacionais. Os resultados também demostram que a formação da capacidade absortiva não é necessariamente dependente da trajetória da organização, podendo ser desenvolvida, ao menos em parte, no contexto de um empreendimento específico.
\end{abstract}

Palavras-chave: Capacidade absortiva; Conhecimento; Colaboração; Semicondutores; Universidade-empresa.

\begin{abstract}
The ability of an organization to identify, assimilate and apply knowledge of the external environment is studied in the field of organizational theories under the theme of "absorptive capacity". The mainstream literature has considered absorptive capacity as a path dependent on the organization's trajectory, which hampers its development in a relatively short time. However, there are studies that show that depending on the kind of knowledge sought, absorptive capacity can be developed in a more specific way. Confronted with this problem, this paper investigates the development of the absorptive capacity of a Brazilian university, facing the challenge of working on a university-industry (U-I) project in the semiconductor industry. The empirical research used the case study as a methodological strategy, through in-depth interviews, taking the UNISINOS - HT Micron project as the unit of analysis. Evidence suggests that the absorptive capacity was enhanced through actions that influenced the initial knowledge base, the training of human resources, the development of the organizational structure, and the establishment of inter-organizational relationships. The results also show that the formation of absorptive capacity is not necessarily path dependent, and it can be developed, at least in part, in the context of a specific project.
\end{abstract}

Keywords: Absorptive capacity; Knowledge; Collaboration; Semiconductors; University-industry.

\section{Introdução}

A capacidade absortiva tem sido um tema de crescente interesse no campo da administração, especialmente pelo fato de estudos (Lane \& Lubatkin, 1998; George et al., 2001; Zahra \& George, 2002; Lane et al., 2006; Xia \& Roper, 2008) terem

destacado que a capacidade de adquirir, assimilar e aplicar o conhecimento de fontes externas geram melhor desempenho competitivo para as organizações.

Alguns autores têm destacado a capacidade absortiva como um "[...] importante elemento na habilidade da

\footnotetext{
${ }^{1}$ Programa de Pós-Graduação em Administração, Universidade do Vale do Rio dos Sinos - UNISINOS, Av. Unisinos, 950, Centro, CEP 99700-000, São Leopoldo, RS, Brasil, e-mail: srossoli@hotmail.com; abalestrin@unisinos.br
} 
organização criar novo conhecimento [...]" (Cohen \& Levinthal, 1989, p. 570), representando, assim, “[...] um dos principais processos para a aprendizagem organizacional [...]" (Lane et al., 2006, p. 833). Dessa forma, percebe-se que a capacidade absortiva representa, na essência, a capacidade de a organização apreender com o seu ambiente, o que implica uma relação direta com os seus resultados de inovação (Murovec \& Prodan, 2009).

Se, por um lado, a literatura sobre capacidade absortiva converge sobre a sua relevância para as organizações, por outro, existem divergências sobre a forma como uma organização poderá desenvolvê-la. A corrente principal da literatura, representada especialmente por Cohen \& Levinthal $(1989,1990)$, tem considerado a capacidade absortiva como uma habilidade dependente de trajetória - path dependent - da organização, o que a torna difícil de ser construída em um espaço relativamente curto de tempo. Entretanto, autores como Lim (2009) defendem que, dependendo do tipo de conhecimento que se pretende adquirir do ambiente externo, a capacidade absortiva poderá ser desenvolvida de maneira mais específica e sem, necessariamente, depender de uma evolução histórica da organização.

Em face dessa problemática, o presente artigo busca investigar o desenvolvimento da capacidade absortiva de uma universidade brasileira, diante do desafio de atuar em um projeto colaborativo junto à indústria de semicondutores. Tal projeto, objeto deste estudo, nasce ancorado em um complexo arranjo colaborativo entre universidade-empresa-governo, incluindo a joint-venture HT Micron, formada por uma empresa sul-coreana (Hana Micron) e uma empresa brasileira (Grupo Parit Participações), uma universidade brasileira (Universidade do Vale do Rio dos Sinos - UNISINOS), além de receber o apoio de políticas públicas das três esferas governamentais brasileiras (municipal, estadual e federal).

Para alcançar o objetivo proposto, o artigo está subdivido em quatro seções, além desta introdução. $\mathrm{Na}$ seção dois, será apresentado o referencial teórico que fundamenta a pesquisa. Na seção três, a metodologia empregada para a coleta e a análise dos dados é detalhada. Na seção quatro, são apresentados e discutidos os principais resultados encontrados. E, na última seção, serão apresentadas as considerações finais do estudo.

\section{Fundamentação teórica}

\subsection{Capacidade absortiva}

Na literatura, alguns autores (Lane \& Lubatkin, 1998; George et al., 2001; Zahra \& George, 2002; Lane et al., 2006; Xia \& Roper, 2008; Murovec \& Prodan, 2009; Camisón \& Fores, 2010; Laursen et al., 2010) destacam que as organizações que são capazes de adquirir, assimilar e aplicar o conhecimento de fontes externas apresentam grandes chances de alcançar um alto nível de inovação e competitividade. Em outras palavras, se uma organização adquire conhecimento ou tecnologia externa sem possuir capacidade tecnológica interna para explorá-lo, dificilmente terá bons resultados de inovação.

Outros autores (Ahuja, 2000; Baum et al., 2000; Hagedoorn \& Duysters, 2002; Chang, 2003; Keil et al., 2008; Lin et al., 2012) destacam o papel relevante da capacidade absortiva na eficácia das alianças estratégicas, defendendo que as empresas necessitam desenvolver sua própria capacidade interna para melhor aproveitar os benefícios da cooperação interorganizacional. Já para autores como Müller-Seitz \& Güttel (2013), os relacionamentos colaborativos e em rede podem fortalecer a capacidade absortiva de uma organização. Nesse sentido, a capacidade absortiva é um componente crucial para o processo de inovação em sentido global, ao mesmo tempo em que é um subproduto das próprias atividades de pesquisa, desenvolvimento e inovação (PDI).

Ao praticar atividades ligadas à pesquisa e ao desenvolvimento de novos produtos e processos, a empresa também está elevando sua eficiência em detectar e captar conhecimento disponível externamente (Cohen \& Levinthal, 1989). Assim, a capacidade absortiva está diretamente relacionada ao estoque de conhecimento prévio que uma organização possui. Tal premissa fundamenta-se em teorias acerca das estruturas cognitivas, as quais sugerem que os conhecimentos já acumulados pelos indivíduos aumentam tanto a capacidade de memorização quanto a de aquisição de novos conhecimentos. No entanto, adverte-se que a capacidade absortiva de uma organização, apesar de depender da capacidade absortiva de seus membros, não se iguala à simples soma dessas capacidades individuais.

Tal especificidade relaciona-se igualmente à capacidade de interação da organização com o seu ambiente e à sua estrutura interna de comunicação. Essa estrutura, por sua vez, depende do papel dos chamados gatekeepers ou boundary-spanners, os quais têm a missão de captar e distribuir a informação no interior da organização e, assim, acionar o mecanismo de sua utilização. Contudo, tais agentes não podem ser confundidos com a capacidade absortiva em si, pois ela é função também da expertise de quem recebe essas informações (Cohen \& Levinthal, 1990). Portanto, a capacidade absortiva consiste em um equilíbrio constante entre a eficiência da comunicação interna, a qual depende de certo grau de sobreposição dos conhecimentos acumulados, e a capacidade das unidades em assimilar e utilizar tais conhecimentos.

Outra questão abordada por Cohen \& Levinthal (1990), a qual está no cerne da temática aqui investigada, 
diz respeito à aquisição e ao desenvolvimento da capacidade absortiva. Para os autores citados, essa capacidade é única e específica da organização e, portanto, o conhecimento externo não pode ser comprado e integrado à sua rotina de maneira automática. Eles postulam o caráter dependente da trajetória da organização (path dependent) da capacidade absortiva, isto é, o seu desenvolvimento acontece por meio de um processo contínuo de aquisição de conhecimento pessoal e organizacional, somado ao aperfeiçoamento dos mecanismos e processos internos de articulação desse conhecimento ao longo do tempo.

Outra abordagem aqui utilizada é a de Lim (2009), cujo trabalho propõe uma tipologia para a capacidade absortiva na qual o parâmetro adotado é a natureza do conhecimento a ser captado externamente. Sua pesquisa deteve-se nos fluxos de conhecimento associados à propagação da produção de semicondutores em cobre, desde o desenvolvimento inicial dessa tecnologia pela IBM até sua adoção generalizada por outras empresas do ramo. O trabalho de Lim (2009) mostrou que, dependendo do estágio no qual se encontra certa inovação dentro de uma indústria, a capacidade absortiva pode existir de três formas diferentes:

a) Capacidade absortiva relativa à disciplina: envolve a aquisição de conhecimento científico básico de determinada tecnologia. A pesquisa encontra-se em fase exploratória e é bastante autônoma, sendo que a absorção de conhecimento se dá primordialmente com a contratação de cientistas especializados na área em questão e da cooperação com a comunidade acadêmica (Lim, 2009).

b) Capacidade absortiva específica do domínio: relaciona-se com a habilidade de assimilar conhecimentos úteis para a solução de problemas reais de determinada área, o que inclui a aplicação comercial de certas descobertas. Essa categoria de capacidade absortiva, segundo Lim (2009), aplica-se quando o processo de PDI de determinada tecnologia está em uma etapa intermediária e é operacionalizada, sobretudo, pela contratação de pessoal já atuante nas pesquisas em andamento, pelo financiamento e pela influência de pesquisas externas.

c) Capacidade absortiva codificada: caracteriza-se pela assimilação do conhecimento já cristalizado em ferramentas e processos. É típica de uma etapa avançada do surgimento da inovação, quando a maturidade da tecnologia permite sua aquisição sem a necessidade de vultosos gastos de PDI, tal como ocorre nos outros dois tipos.
Conforme apresentado anteriormente, na literatura sobre o tema, prevalece a visão mais tradicional que considera a capacidade absortiva como uma habilidade dependente da trajetória da organização, o que a torna difícil de ser desenvolvida em um espaço de tempo relativamente curto (Cohen \& Levinthal, 1990; Zahra \& George, 2002). Todavia, o estudo aqui empreendido ampara-se no posicionamento adotado por Lim (2009), segundo o qual as características da capacidade absortiva a ser praticada pela organização, assim como o processo pelo qual ocorre o seu desenvolvimento, está estritamente relacionado ao tipo de conhecimento que se pretende adquirir. Nesta perspectiva, se esse conhecimento estiver em fase inicial de desenvolvimento científico, o processo pelo qual se dá o estabelecimento da capacidade absortiva relacionada é mais longo e complexo, estando profundamente arraigada à trajetória da organização.

De maneira oposta, se esse conhecimento estiver em etapa mais avançada, já incorporado a uma tecnologia específica, poderá ocorrer de maneira menos complexa e mais rápida, sem a exigência de amplos esforços e investimentos em PDI. Tal configuração da capacidade absortiva de uma organização, no entanto, dependerá do equilíbrio de seus quatro elementos fundamentais, conforme detalhados na próxima seção.

\subsection{Principais elementos da capacidade absortiva}

A literatura tem evidenciado quatro elementos principais que compõem a capacidade absortiva e que serão explorados na sequência desta seção: a base de conhecimento de uma organização, os recursos humanos internos, a estrutura organizacional e as relações interorganizacionais.

\subsubsection{A base de conhecimento}

O domínio de conhecimento da organização está na raiz do conceito de capacidade absortiva organizacional. Para Cohen \& Levinthal (1990), a habilidade para avaliar e utilizar o conhecimento externo é amplamente uma função do nível de conhecimento prévio relacionado. Segundo os autores, "[...] o conhecimento prévio confere uma habilidade de reconhecer o valor de uma nova informação, assimilá-la e aplicá-la em finalidades comerciais. Essas habilidades coletivamente constituem o que nós chamamos de 'capacidade absortiva' da empresa [...]” (Cohen \& Levinthal, 1990, p. 128). Fica claro nessa citação a importância atribuída às atividades de PDI praticadas pela empresa para a formação de seu estoque de conhecimento.

Essa conexão é tradicionalmente adotada por grande parte dos acadêmicos que estudam o tema. Para eles, a base de conhecimento de uma organização 
que permite a absorção de novo conhecimento é gerada predominantemente pelas atividades ligadas à pesquisa científica e ao desenvolvimento de inovações no interior da empresa. Murovec \& Prodan (2009) salientam, inclusive, que a competência de PDI tem sido reconhecida como sendo essencial para a capacidade absortiva na maior parte dos estudos em torno desse tema. Outros autores, como Zahra \& George (2002), também enfatizam a importância do conhecimento acumulado pela organização para o desenvolvimento da capacidade absortiva, o qual teria como origem tanto a trajetória da empresa, consubstanciado em sua experiência, quanto as fontes externas a ela.

Daghfous (2004) cita a base de conhecimento de uma organização como elemento central da capacidade absortiva, argumentando que quanto mais desenvolvida estiver essa base mais fluida será a incorporação de novo conhecimento. Além disso, destaca-se também o papel desempenhado pelo investimento em PDI que, de acordo com Veugelers (1998), as informações e habilidades geradas por tais esforços contribuem para a base de conhecimento da organização, fazendo com que ela se torne preparada para se beneficiar dos chamados spillovers da atividade de inovação tecnológica.

O desenvolvimento de atividades internas de PDI também é um indicador associado à base de conhecimento que uma organização detém (Vega-Jurado et al., 2008) e influencia positivamente o grau de desenvolvimento da sua capacidade absortiva (Murovec \& Prodan, 2009), principalmente daquela que se destina à aquisição de conhecimento científico (Schmidt, 2010).

Tais evidências teóricas permitem a formulação da primeira proposição da pesquisa (Proposição 1 - P1): a base inicial de conhecimento da organização influencia o desenvolvimento de sua capacidade absortiva. Essa proposição indica que a capacidade absortiva de uma organização será diretamente influenciada pelo estoque inicial de conhecimento que ela apresenta, ou seja, dificilmente uma organização terá uma capacidade absortiva significativa em uma área em que não possua qualquer conhecimento anteriormente desenvolvido. Essa proposição é ainda mais pertinente quando se trata de uma capacidade absortiva que deverá ser desenvolvida em uma área de elevada complexidade tecnológica e em um curto espaço de tempo.

\subsubsection{Recursos humanos}

Cohen \& Levinthal (1990), como já indicado, sustentam que a capacidade absortiva coletiva depende, em grande parte, das capacidades absortivas individuais. Essa conexão entre a capacidade absortiva da organização e a das pessoas que a compõem remete, inevitavelmente, ao nível de qualificação dos funcionários. A partir daí, vários autores passaram a considerar a elevada influência desse elemento sobre a capacidade absortiva (Vinding, 2006; Vega-Jurado et al., 2008).

Para Vinding (2006), por exemplo, o próprio conhecimento da empresa pode ser equiparado ao nível de capacitação formal de seus funcionários, o qual, por sua vez, terá como indicador o percentual de empregados com algum grau acadêmico. Nessa abordagem da capacidade absortiva voltada ao capital humano, o autor também inclui as práticas de gestão de recursos humanos, as quais seriam responsáveis por viabilizar a integração dos conhecimentos individuais na organização. Inserem-se no escopo de tais práticas os grupos de trabalho interdisciplinares, os círculos de qualidade e a rotação e integração de funções.

Para Daghfous (2004), empregados com elevado grau de formação em uma área particular são normalmente mais aptos a adquirir novo conhecimento, o que torna, portanto, o número suficiente de especialistas, cientistas e engenheiros um elemento importante da capacidade absortiva da organização. Vega-Jurado et al. (2008) igualmente situam o nível de qualificação da força de trabalho como um fator precípuo na determinação da capacidade absortiva. Para esses autores " [...] empresas cujos funcionários são altamente qualificados e capacitados terão níveis mais elevados de capacidade absortiva [...]" (Vega-Jurado et al., 2008, p. 396).

Percebe-se que uma parte significativa dos estudos existentes examina a importância do grau de educação formal dos empregados, mas negligencia a importância dos investimentos em capacitações efetuados pela própria empresa, os quais costumam estar mais direcionados para suas necessidades específicas (Murovec \& Prodan, 2009). Nesse sentido, além da educação tradicional (cursos de graduação, especialização, mestrado e doutorado) dos funcionários, as capacitações internas e externas, oferecidas diretamente pela empresa, também influenciam a capacidade por meio da qual a organização absorverá conhecimento do seu entorno. Essa possibilidade é, inclusive, sugerida por Cohen \& Levinthal (1990, p. 129), os quais afirmam que as "[...] empresas também investem diretamente em capacidade absortiva quando enviam pessoal para capacitações técnicas avançadas".

A contratação de cientistas e estudantes com vistas a incrementar a capacidade absortiva é outra estratégia mencionada por Lim (2009). Esse autor defende, porém, que o tipo de profissional contratado deve ser compatível com o conhecimento a ser adquirido pela organização. Assim, devem ser admitidos pesquisadores de áreas mais fundamentais para o caso em que o conhecimento a ser absorvido seja do tipo mais básico ou, de campos mais aplicados, se o objetivo for adquirir uma tecnologia já desenvolvida (Lim, 2009). 
Com base nessas considerações, emerge a segunda proposição de pesquisa (Proposição $2-\mathrm{P} 2$ ): os recursos humanos da organização influenciam o desenvolvimento da sua capacidade absortiva. Este artigo baseia-se na ideia de que as ações que têm por objetivo promover a formação e a capacitação de pessoas em determinada área apresentam o potencial de incrementar a capacidade absortiva da organização.

\subsubsection{Estrutura organizacional}

A estrutura organizacional é outro elemento bastante citado na literatura sobre capacidade absortiva. O artigo seminal de Cohen \& Levinthal (1990), apesar de não tratar explicitamente desse fator como um antecedente para essa capacidade, situa sua relevância no processo de amplificação da capacidade absortiva do nível individual para o organizacional. Um elemento crucial nessa dinâmica, de acordo com Cohen \& Levinthal (1990), é a estrutura de comunicação vigente na empresa, a qual estabelece a conexão tanto entre a empresa e seu meio externo quanto entre suas unidades constituintes. Nesse sentido, os gatekeepers e boundary-spanners, em razão de sua capacidade de averiguação, tradução e distribuição de conhecimento vindo de fora, exercem um papel fundamental.

Nessa perspectiva, a estrutura organizacional tende a afetar a capacidade absortiva principalmente durante o processo de disseminação do conhecimento captado, quando ocorre sua difusão por todas as partes da organização (Daghfous, 2004). Entretanto, o grau de formalização, ou seja, a extensão na qual os procedimentos, as regras e as instruções guiam os processos da organização, também constitui a estrutura organizacional (Vega-Jurado et al., 2008). Além disso, uma estrutura mais horizontal, que permite e incentiva a socialização de conhecimento (Daghfous, 2004) e uma cultura mais tolerante a mudanças, que favorece a entrada de conhecimento externo (Murovec \& Prodan, 2009), são consideradas igualmente relevantes nesse contexto.

Com a finalidade de investigar como a estrutura organizacional pode afetar o desenvolvimento da capacidade absortiva, é formulada a terceira proposição (Proposição 3 -P3): a configuração da estrutura de uma organização influencia o desenvolvimento da sua capacidade absortiva. Assim, acredita-se que a estrutura organizacional impacta a maneira como uma organização adquire e processa o conhecimento de fontes externas.

\subsubsection{Relações interorganizacionais}

A fim de construir ou melhorar sua capacidade absortiva, a empresa também pode estabelecer vínculos com outras organizações para, assim, expandir sua base de conhecimento e também enriquecer a qualificação e a experiência de seus colaboradores. Como resultado, as capacidades absortivas individuais são alavancadas no todo e a capacidade absortiva da organização é ampliada (Cohen \& Levinthal, 1990). Zahra \& George (2002) também consideram as relações interorganizacionais um elemento importante da capacidade absortiva, pelo fato de ser uma potencial fonte de conhecimento para a empresa (Balestrin et al., 2008).

Na mesma linha, Daghfous (2004) afirma que a intensidade dos relacionamentos com as demais organizações, tais como instituições acadêmicas, empresas de suporte técnico e consultorias, são capazes de incrementar a capacidade absortiva da organização. Vinding (2006) igualmente insere esse fator em seu modelo de análise, diferenciando-o em relacionamentos com clientes e fornecedores, de um lado, e com instituições de conhecimento (universidades e institutos de pesquisa), de outro. Seu estudo, conduzido em 1.544 empresas dinamarquesas, revelou que relações próximas com esses dois tipos de atores constituem um fator positivamente correlacionado com a habilidade de inovar.

Lançando mão de uma denominação diferente para o mesmo fenômeno, outros autores elegem a "cooperação" (Murovec \& Prodan, 2009, p. 861) como um dos elementos da capacidade absortiva. Essa cooperação igualmente abrange parcerias com atores de diversos tipos, como empresas, fornecedores, clientes, competidores, consultores, laboratórios de PDI, universidades e governo, entre outros. Tal como Vinding (2006), Murovec \& Prodan (2009) também encontraram suporte empírico para a relação entre cooperação e capacidade absortiva, reforçando ainda mais essa conexão.

Já o estudo sobre os fluxos de conhecimento na indústria de semicondutores, realizado por Lim (2009), aponta a importância dos vínculos externos para o desenvolvimento dessa capacidade organizacional. Esses vínculos podem ser estabelecidos com a comunidade de cientistas, no caso da capacidade relativa à disciplina e específica do domínio, as quais são mais voltadas à ciência básica; ou com empresas detentoras de tecnologia já desenvolvida, quando se trata da capacidade absortiva codificada, a qual se refere ao conhecimento já aplicado a produtos e processos (Lim, 2009).

Depreende-se, então, a quarta proposição da pesquisa (Proposição 4-P4): as relações interorganizacionais estabelecidas pela organização influenciam o desenvolvimento de sua capacidade absortiva. Todas as formas pelas quais a organização interage com o ambiente que a cerca, principalmente com aqueles atores detentores de conhecimento que lhe interessa, colaboram para o fomento de sua capacidade absortiva. 
O desenvolvimento das quatro proposições de pesquisa, a partir do referencial teórico consultado, possibilitou a construção de um esquema conceitual sobre o desenvolvimento da capacidade absortiva, conforme representado na Figura 1.

$\mathrm{O}$ esquema indica que a capacidade absortiva pode ser influenciada por quatro elementos centrais: a base de conhecimento (P1), os recursos humanos (P2), a estrutura organizacional (P3) e as relações interorganizacionais (P4). Acredita-se que o processo de desenvolvimento dessa capacidade passa necessariamente pela realização de ações que visem o fortalecimento de tais elementos.

\section{Metodologia da pesquisa}

A estratégia de pesquisa utilizada foi o estudo de caso, definido por Wacheux (1996, p. 89) como “[...] uma análise espacial e temporal de um fenômeno complexo pelas condições, pelos eventos, pelos atores e pelas implicações". As características desse método de pesquisa são adequadas em situações em que o investigador apresenta pouca possibilidade de controle sobre os eventos, geralmente contemporâneos, em um contexto da vida real (Yin, 1994) e para estudar um fenômeno em profundidade sem ter a preocupação com a representatividade estatística ou a amplitude do alcance dos resultados, mas sim com a verticalidade do caso selecionado (Benbasat et al., 1987).

Para a presente pesquisa, buscou-se levantar evidências empíricas em um projeto colaborativo que está sendo implementado entre a UNISINOS e a empresa HT Micron, no contexto da indústria brasileira de semicondutores. Quanto à unidade de análise adotada, embora este estudo esteja inserido no contexto de um projeto que inclua as duas organizações mencionadas, o foco deste trabalho deteve-se na universidade envolvida. Dessa forma, pretendeu-se analisar o processo de desenvolvimento da capacidade absortiva dessa instituição, e não o projeto de colaboração como um todo.

Autores como Benbasat et al. (1987) e Yin (1994) destacam que a robustez de um estudo de caso vem da utilização de múltiplas fontes de evidência (indivíduos, grupos, organizações) e de múltiplas técnicas de coleta de dados, por exemplo, observação direta ou indireta, análise de documentos, entrevistas e dados secundários. No entanto, mesmo sendo amplamente recomendado, a utilização de complementaridade e triangulação de diferentes técnicas de coleta de dados, Eisenhardt (1989), em seu seminal artigo sobre estudo de caso, salienta que "[...] alguns investigadores empregaram

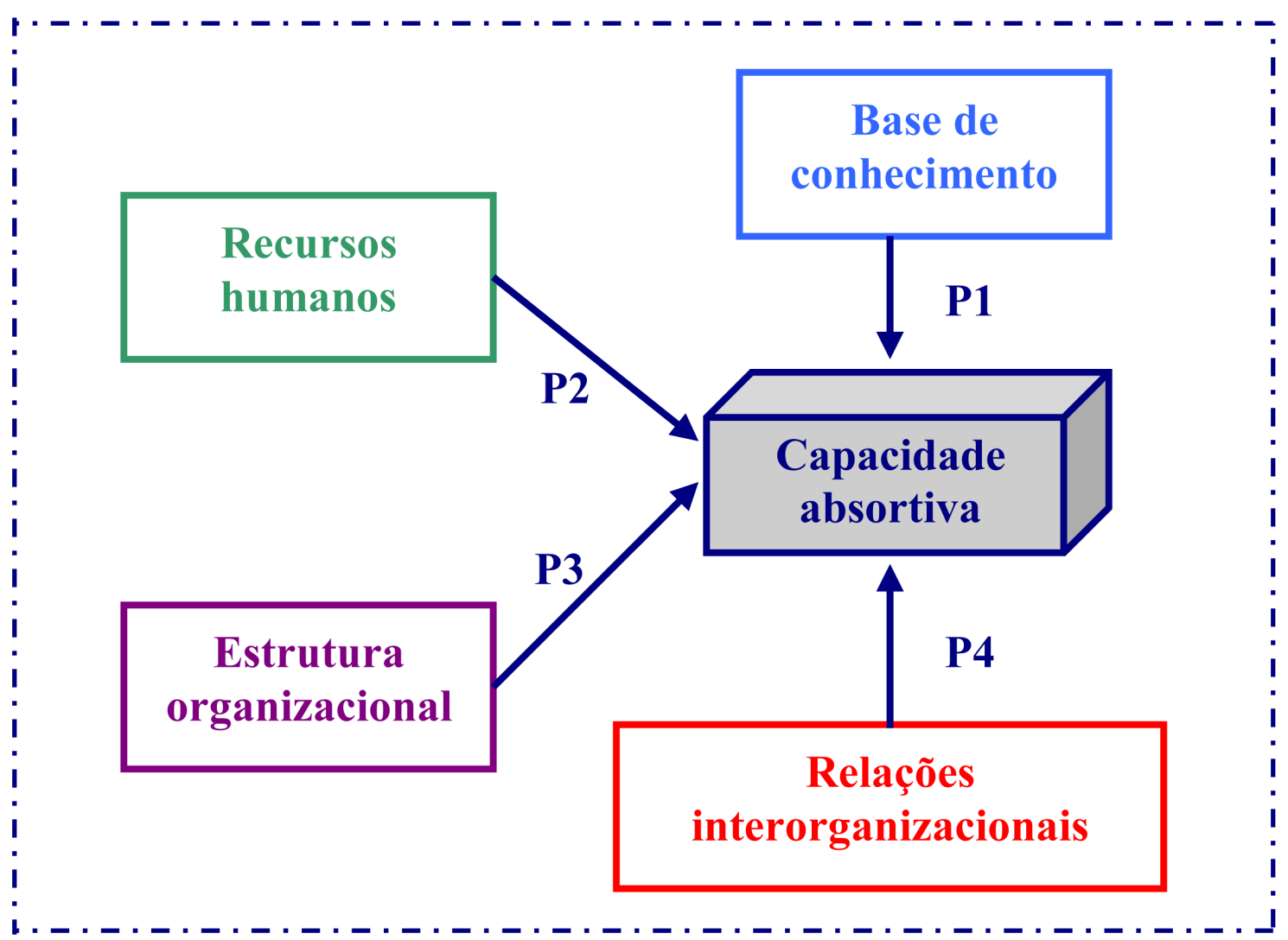

Figura 1. Esquema conceitual da pesquisa. Fonte: Elaborada pelos autores. 
somente uma técnica de coleta de dados, como, por exemplo, Gersick (1988) que utilizou somente observação ou Bettenhausen \& Murnighan (1986) que utilizaram somente dados quantitativos de laboratório [...]" Eisenhardt (1989, p. 537). Independentemente das técnicas de coleta de dados utilizadas, para Yin (1994), o pesquisador deve certificar-se de que as evidências empíricas levantadas são suficientes para a compreensão do fenômeno.

A coleta de dados de campo do caso UNISINOS - HT Micron foi feita por meio da técnica de entrevistas em profundidade, amparadas por meio de um questionário semiestruturado, cujas questões originaram-se das variáveis apresentadas no Quadro 1. Ao todo, foram entrevistados dez profissionais, cinco deles da UNISINOS (quatro pesquisadores e um executivo responsável pelo projeto) e outros cinco externos à instituição (um assessor de ciência e tecnologia da embaixada do Brasil na Coreia do Sul, um executivo da HT Micron, um representante da área de microeletrônica do Ministério de Ciência, Tecnologia e Inovação, uma secretária adjunta da Secretaria de Ciência e Tecnologia do Estado do Rio Grande do Sul e um consultor de empresa que assessora o projeto de semicondutores na UNISINOS), os quais contribuíram com uma visão externa à UNISINOS acerca do projeto.
As entrevistas foram realizadas individualmente e duraram entre 30 e 90 minutos, permitindo aos entrevistados tanto aprofundar tópicos contemplados no roteiro de questões quanto levantar outras questões e perspectivas não previstas nas etapas anteriores da pesquisa. Além disso, a abordagem em cada entrevista pretendeu ser condizente com a expertise apresentada por cada respondente, isto é, com os conhecimentos próprios de sua formação acadêmica, trajetória profissional e área de atuação. Por questões idiossincráticas ao caso, especialmente relacionadas a clausulas de sigilo e confidencialidade, outras fontes de dados, como documentos e observação participante não foram utilizadas. Mesmo que a utilização de uma única fonte de coleta de dados não seja o mais recomendado pela literatura, a amplitude dos respondentes e a profundidade das entrevistas realizadas permitiram uma significativa robustez das evidências empíricas para a compreensão do caso estudado.

Com o objetivo de registrar as informações assim obtidas, todas as entrevistas foram gravadas, transcritas e agrupadas de acordo com as variáveis de análise presentes no Quadro 1. Conforme as transcrições foram sendo concluídas, os extratos considerados importantes, à luz dos fundamentos teóricos utilizados, foram sendo destacados para permitir a interpretação dos resultados.

Quadro 1. Operacionalização da pesquisa.

\begin{tabular}{|c|c|}
\hline Proposições da pesquisa & Variáveis \\
\hline $\begin{array}{l}\text { P1: A base inicial de conhecimento } \\
\text { da organização influencia o } \\
\text { desenvolvimento de sua capacidade } \\
\text { absortiva. }\end{array}$ & $\begin{array}{l}\text { - Atividades de PDI na área de semicondutores. } \\
\text { - Atividades de PDI em áreas relacionadas. } \\
\text { - Resultados de PDI (artigos, livros, dissertações, teses, trabalhos } \\
\text { técnicos, patentes) na área de semicondutores. } \\
\text { - Resultados de PDI (artigos, livros, dissertações, teses, trabalhos } \\
\text { técnicos, patentes) em áreas relacionadas. }\end{array}$ \\
\hline $\begin{array}{l}\text { P2: Os recursos humanos da } \\
\text { organização influenciam o } \\
\text { desenvolvimento de sua capacidade } \\
\text { absortiva. }\end{array}$ & $\begin{array}{l}\text { - Presença de estudantes, especialistas, cientistas e engenheiros. } \\
\text { - Qualificação formal do pessoal envolvido no projeto. } \\
\text { - Capacitação com foco no projeto. }\end{array}$ \\
\hline $\begin{array}{l}\text { P3: A configuração da estrutura } \\
\text { de uma organização influencia o } \\
\text { desenvolvimento da sua capacidade } \\
\text { absortiva. }\end{array}$ & $\begin{array}{l}\text { - Estrutura de PDI (centros e unidades de pesquisa e pós-graduação, } \\
\text { grupos de pesquisa, laboratórios, equipamentos). } \\
\text { - Estrutura de comunicação. } \\
\text { - Pessoas-chave (gatekeepers ou boundary-spanning, lideranças). } \\
\text { - Formalização e registro do conhecimento. } \\
\text { - Processo decisório/estrutura hierárquica. } \\
\text { - Tolerância à mudança. }\end{array}$ \\
\hline $\begin{array}{l}\text { P4: As relações interorganizacionais } \\
\text { estabelecidas pela organização } \\
\text { influenciam o desenvolvimento de sua } \\
\text { capacidade absortiva. }\end{array}$ & $\begin{array}{l}\text { - Relações com clientes, fornecedores e empresas. } \\
\text { - Relações com universidades e órgãos de pesquisa. } \\
\text { - Acordos de cooperação em pesquisa na área do projeto e afins. } \\
\text { - Intercâmbio de pesquisadores e estudantes. } \\
\text { - Realização de eventos com organização externa. }\end{array}$ \\
\hline
\end{tabular}

Fonte: Elaborado pelos autores. 


\section{Análise e interpretação dos resultados}

\subsection{O projeto UNISINOS - HT Micron}

Mesmo sendo uma indústria pujante no cenário internacional, a produção de semicondutores no Brasil é incipiente. Depois de um período de relativo êxito, estimulado pelos investimentos da Telebras em pesquisas na área nas décadas de 1970 e 1980 e, sobretudo, pela reserva de mercado decorrente da Política Nacional de Informática (1984-1992), a atual produção de semicondutores sofreu uma forte redução, tornando-se insignificante para as demandas da indústria nacional. Segundo Ripper (2004), tal solapamento deve-se a dois fatores principais: a criação da Zona Franca de Manaus, que favoreceu a fabricação de bens eletrônicos de consumo com tecnologia e insumos estrangeiros, incluindo os semicondutores, e a abertura das importações de equipamentos pelo governo do então presidente Fernando Collor de Mello (1990-1992), o que inviabilizou a produção doméstica de tais componentes.

Nos últimos anos, porém, algumas iniciativas nas esferas governamental (como o Programa de Apoio ao Desenvolvimento Tecnológico da Indústria de Semicondutores e Displays - PADIS), acadêmica (como o desenvolvimento de centros de pesquisa) e empresarial (como a realização de investimentos em novos empreendimentos) sinalizam uma oportunidade para o Brasil viabilizar essa indústria ainda nessa próxima década.

Para compreender melhor a estrutura da indústria de semicondutores, destaca-se que o processo de produção compreende três etapas distintas: a) projeto (design): fase em que a estrutura do semicondutor é definida e ocorre em plantas conhecidas como design houses; b) fabricação (front-end): fase em que o projeto gerado na etapa anterior parte para a produção, cujo resultado é uma lâmina de silício chamada de wafer; c) encapsulamento e teste (back-end): fase em que o wafer é beneficiado para gerar os chips individuais, testados e preparados para a comercialização.

O back-end, portanto, apresenta-se como uma etapa dotada de maior aplicabilidade industrial, já que se encontra no final da cadeia produtiva de semicondutores (ver Figura 2). Contudo, o esgotamento iminente da redução das dimensões do chip passou a exigir o desenvolvimento de novas tecnologias de encapsulamento para permitir o contínuo avanço na capacidade de processamento dos semicondutores. Nessa perspectiva, atualmente uma parcela importante das pesquisas na área destina-se a estudar formas eficientes de "empilhamento" de chips.

O projeto colaborativo estabelecido entre a UNISINOS e a HT Micron diz respeito à instalação de uma infraestrutura científico-tecnológica específica para a etapa de encapsulamento e teste de semicondutores junto ao campus dessa universidade. $\mathrm{O}$ acordo de cooperação consiste na cessão, por parte da UNISINOS, do terreno para a construção da fábrica e o custeio de sua construção, a qual será repassada à HT Micron por meio de um contrato de locação. À HT Micron cabe a aquisição dos equipamentos necessários ao funcionamento da fábrica, bem como a importação e a instalação da tecnologia requerida no processo de encapsulamento de semicondutores.

Esse acordo de cooperação, porém, não se refere somente à construção das instalações produtivas da HT Micron; ele também inclui o desenvolvimento de uma infraestrutura de pesquisa na área de encapsulamento de semicondutores. A HT Micron, como qualquer outra empresa nessa área, poderá beneficiar-se de incentivos fiscais da lei do PADIS, mas deverá aplicar, como contrapartida, um investimento mínimo de 4\% do faturamento em P\&D. Portanto, a existência de uma infraestrutura de pesquisa e desenvolvimento (P\&D) por parte da universidade é fundamental para que a HT Micron, ou qualquer outra empresa do setor, possa aplicar aos recursos do PADIS em P\&D e beneficiar-se dos incentivos fiscais.

Para a UNISINOS, o investimento no projeto sistêmico de semicondutores (construção da planta produtiva, do instituto tecnológico de semicondutores - itt CHIP e de novos cursos de formação acadêmica) torna-se de elevado interesse estratégico, especialmente pelas externalidades positivas que tal projeto gerará a toda a universidade, especialmente nas áreas de engenharias. O itt CHIP, cujo projeto está em fase de implementação, atuará não só como um centro de pesquisas em encapsulamento de semicondutores, mas também como um locus de capacitação de recursos humanos na área. Nessa perspectiva, o projeto UNISINOS - HT Micron tem, em um primeiro momento, uma meta tangível para ambos os atores, que é a construção de uma planta industrial apta a encapsular e testar

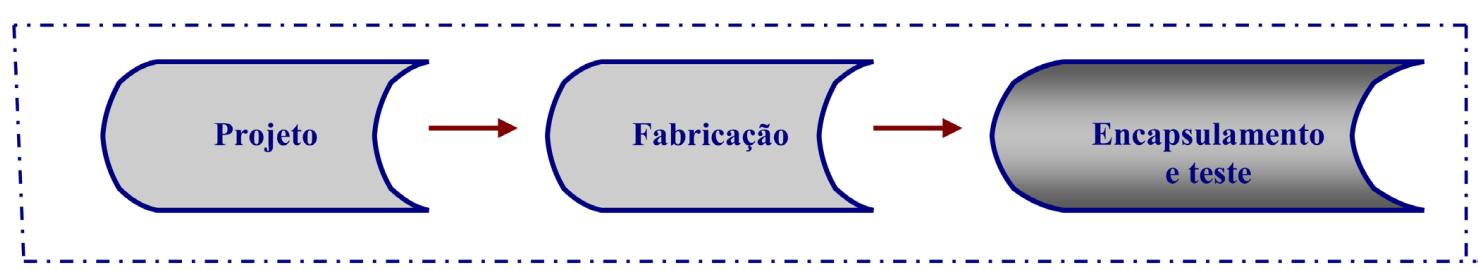

Figura 2. Etapas do processo de produção de semicondutores. Fonte: Elaboração dos autores, com base em informações obtidas na pesquisa. 
semicondutores. No entanto, é possível afirmar que seu escopo ultrapassa esse objetivo, já que a proposta engloba ainda a construção de um complexo científico-tecnológico destinado à pesquisa aplicada e à formação de profissionais para a área.

Para fazer frente à complexidade tecnológica que o projeto envolve, a capacidade de absorção de conhecimentos externos por parte da UNISINOS também passa a ser mais exigida, o que torna a dinâmica necessária para o seu desenvolvimento mais desafiadora. Assim, o processo de desenvolvimento dessa capacidade deve incluir tanto ações pontuais, com efeitos imediatos, quanto iniciativas cujo desenvolvimento ocorra em um período mais longo de tempo.

\subsection{O desenvolvimento da capacidade absortiva da UNISINOS}

A análise dos resultados sobre o desenvolvimento da capacidade absortiva da UNISINOS no projeto sistêmico de semicondutores está configurada de acordo com os elementos da Figura 1 e apresentada na sequência do texto.

\subsubsection{A Base de conhecimento}

Quando a UNISINOS tomou a decisão, em 2009, de desenvolver o projeto colaborativo com a HT Micron, já contava com uma base de conhecimento científico-tecnológico, representada pela existência de dez cursos de graduação em engenharia, cinco programas de pós-graduação em áreas tecnológicas e algumas dezenas de projetos de pesquisa em áreas afins. Esses projetos e cursos não estavam diretamente ligados à área de semicondutores, mas representavam uma base razoável de conhecimento, inclusive pelo fato de a produção de semicondutores ser, por natureza, uma área interdisciplinar de conhecimentos de engenharia, física e química, conforme relatou um pesquisador da UNISINOS: "[...] se não houvesse pessoas aqui dentro que tivessem conhecimentos correlatos a esse assunto, seria muito mais complexo. Como o ambiente acadêmico permite que haja pessoas com conhecimentos correlatos, isso acaba, sem dúvida, sendo um alicerce e facilitando esse processo".

No que tange às iniciativas que visam incrementar essa dimensão da capacidade absortiva da UNISINOS, uma delas refere-se à criação de novos cursos relacionados às áreas ligadas ao encapsulamento de semicondutores e também à reestruturação da grade curricular de cursos já existentes, com a inclusão de disciplinas ligadas a essa tecnologia. Nesse escopo, foram criados dois novos cursos de graduação: engenharia química e engenharia de materiais. A graduação em engenharia elétrica passou a apresentar três opções de ênfase: elétrica, eletrônica e controle e automação.
Além disso, houve a criação do mestrado profissional em engenharia elétrica, com linhas de atuação em manufatura eletrônica, aplicada ao encapsulamento de semicondutores e funcionará junto ao itt CHIP.

Quanto ao itt CHIP em si, insere-se no conjunto de ações relacionadas ao desenvolvimento do conhecimento e da capacidade tecnológica da UNISINOS na área de back-end. Concebido com o intuito de atuar em atividades de PDI em parceria com a HT Micron, o itt CHIP também terá como atribuição desenvolver pesquisas para outras instituições e empresas brasileiras na área de encapsulamento e testes de semicondutores.

Tais evidências estão alinhadas com a Proposição 1 da pesquisa, ou seja, o estoque inicial de conhecimento científico em áreas afins vem sendo fundamental para a UNISINOS desenvolver sua capacidade absortiva na área de encapsulamento de semicondutores.

\subsubsection{Recursos humanos}

Uma das primeiras iniciativas para incrementar a capacidade absortiva da UNISINOS no que se refere aos seus recursos humanos foi a contratação de três especialistas em semicondutores com reconhecida experiência nesse campo. Entre as atividades desse grupo de especialistas, a principal foi sugerir e orientar as ações subsequentes da UNISINOS no desenvolvimento do projeto de criação do itt CHIP e do Mestrado Profissional com ênfase em encapsulamento de semicondutores. Também foram contratados novos professores oriundos de instituições brasileiras e internacionais com conhecimentos em semicondutores a fim de aprimorar a formação de um quadro de cientistas nessa área dentro da universidade.

Dentre as iniciativas referentes aos recursos humanos, destaca-se, nos anos de 2010 e 2011, a ida de seis pesquisadores da UNISINOS cursar pós-doutorado em universidades sul-coreanas. A permanência dos pesquisadores na Coreia do Sul por um período de cinco meses teve diversas finalidades, entre as quais se destacaram: promover a formação em nível de pós-doutorado em áreas relacionadas ao desenvolvimento de semicondutores, inserir os pesquisadores no contexto produtivo da empresa sul-coreana Hana Micron (uma das empresas que forma a joint-venture HT Micron), estabelecer acordos de cooperação com universidades daquele país e aprimorar o projeto de criação do itt CHIP e do Mestrado Profissional na UNISINOS. Outro fato relevante foi o envio de alunos para a Coreia do Sul, dentro do Programa do Governo Federal "ciências sem fronteiras". No final do ano de 2014, a UNISINOS já havia enviado mais de 50 alunos para universidades sul-coreanas, sendo, naquele momento, uma das universidades brasileiras com o maior número de alunos enviados para aquele país dentro do escopo do Programa. 
O conhecimento adquirido pelos pesquisadores constituiu um passo fundamental na formação da capacidade absortiva da UNISINOS relativa ao projeto com a HT Micron, fornecendo uma visão ampla de toda a etapa de back-end. Nas palavras de um dos pesquisadores, o qual fez parte dessa missão, a postura predominantemente adotada pela equipe enviada não era de acadêmicos, mas sim de aprendizes: "Jamais demos a entender que éramos experts. Muito pelo contrário. Estávamos lá para aprender, porque nenhum de nós trabalhava nessa área". Essa etapa foi essencial para a formação da capacidade absortiva da UNISINOS relativa à parceria com a HT Micron, pois forneceu uma visão ampla de toda a etapa de back-end, conforme outro trecho da entrevista com o pesquisador: "Foi uma oportunidade impar [...] não só de aprender e aprofundar as questões em relação a encapsulamento e semicondutores [...], mas também para entender como funciona o negócio da Hana Micron, o back-end".

As evidências empíricas do estudo indicaram que as ações de qualificação dos recursos humanos foram fundamentais, principalmente, para as primeiras fases da concretização do projeto. Todavia, no decorrer do avanço de atuação da universidade nas atividades científico-tecnológicas demandadas na consolidação do itt CHIP, o contingente de pessoas capacitadas, segundo a maioria dos entrevistados, deverá ser fortalecido. Portanto, o desenvolvimento da capacidade absortiva da UNISINOS via recursos humanos ainda está em sua etapa inicial.

Essa evidência, contudo, não impediu a observação de que há influência da qualificação de recursos humanos no desenvolvimento da capacidade absortiva da universidade quanto ao projeto em estudo, o que se alinha à Proposição 2 da pesquisa.

\subsubsection{Estrutura organizacional}

As variáveis referentes à estrutura organizacional incluem a estrutura de PDI, a estrutura de comunicação, a presença de pessoas-chave, o processo decisório e a tolerância à mudança. No que tange à estrutura de PDI nas áreas afins ao encapsulamento de semicondutores, a UNISINOS dispunha de uma infraestrutura ainda pouco desenvolvida até o início do projeto. Porém, com a criação de novas graduações em engenharia (elétrica, eletrônica, química e materiais), do mestrado profissional em engenharia elétrica, com ênfase em encapsulamento de semicondutores, bem como, com a implantação o itt CHIP, a universidade vem avançando rapidamente na instalação de uma infraestrutura de excelência no desenvolvimento de recursos humanos e de P\&D na área de encapsulamento de semicondutores. Cabe também ressaltar o empenho e o investimento realizado pela universidade na construção da planta produtiva da HT Micron, no
Parque Tecnológico TECNOSINOS, tornando-se a maior e a mais moderna planta de encapsulamento de semicondutores da américa latina.

No que tange à estrutura de comunicação da UNISINOS, especialmente à socialização de conhecimentos adquiridos no contexto desse empreendimento na área de semicondutores, a universidade vem promovendo anualmente, desde 2011, o Fórum Brasil - Coreia do Sul em Ciência, Tecnologia e Inovação. Esse evento aborda a temática da indústria de semicondutores no Brasil e na Coreia do Sul, suas oportunidades e seus desafios. Conta com a presença de especialistas e pesquisadores em semicondutores, tanto brasileiros quanto sul-coreanos, além de representantes do governo responsáveis pela política de estímulo ao setor. O objetivo central das edições desse fórum é incentivar a discussão em torno do desenvolvimento científico e tecnológico vinculados ao tema de semicondutores e de oportunidades de cooperação técnico-científica entre os dois países.

No que concerne ao registro e à formalização do conhecimento, o processo vem sendo desenvolvido. Exemplo disso foi a sistematização do conhecimento obtido pela equipe enviada à Coreia do Sul por meio de cursos de capacitação em encapsulamento de semicondutores, os quais estão sendo ofertados na Universidade. Os principais responsáveis pela preparação desses cursos, e também pela coordenação geral do processo de disseminação de conhecimento, são três professores que correspondem às figuras de gatekeepers ou boundary-spanners, ou seja, indivíduos que têm por tarefa escrutinar o ambiente externo em busca de conhecimentos relevantes, importá-los para a organização e promover sua eficiente comunicação ao público interno.

O processo decisório da UNISINOS foi outra variável estudada, pelo fato de interferir na velocidade com que o conhecimento é captado e transmitido pela organização. Os dados coletados sugerem que a dinâmica que rege a tomada de decisões na universidade caracteriza-se por ser mais colegiada e participativa, envolvendo diversos níveis hierárquicos na sugestão de melhorias, com acesso direto à alta administração, conforme destacou um dos pesquisadores: "Temos participado de reuniões e sido chamados para opinar em relação a prioridades a serem tomadas. [...] A UNISINOS vem promovendo a oportunidade de termos contato com a alta administração, de forma a sermos ouvidos".

Por fim, no que se refere ao grau de tolerância à mudança ocasionada pelo ingresso da UNISINOS no projeto com a HT Micron, o trabalho de campo não indicou evidências de resistência. Tal fato leva a crer que a comunidade interna da instituição - e especialmente a parcela acadêmica ligada ao projeto - aceitou a proposta, o que contribui para o fortalecimento da capacidade absortiva associada a tal parceria. 
Verifica-se, assim, a influência da estrutura organizacional no desenvolvimento da capacidade absortiva, o que corrobora a Proposição 3. Parte dessas ações tem o potencial de contribuir para o desenvolvimento da capacidade absortiva de longo prazo da UNISINOS, como a consolidação do itt CHIP e o desenvolvimento de cursos e competências nessa área.

\subsubsection{Relações interorganizacionais}

Além de manter diversos tipos de relacionamentos com público externo, como alunos, empresas, órgãos do governo e demais instituições de ensino, a Universidade tem avançado rapidamente no estabelecimento de novas parcerias estratégicas. Nesse sentido, os laços mais importantes vêm sendo desenvolvidos com instituições sul-coreanas, em especial com a SKKU University, a Sogang University e o Korea Advanced Institute of Science and Technology (KAIST).

$\mathrm{O}$ estreitamento da ligação entre a UNISINOS e as instituições sul-coreanas, sejam elas universidades ou empresas, tem se apresentado como um aspecto relevante para agilizar a capacitação de profissionais na área de semicondutores. A assinatura de acordos de cooperação com universidades sul-coreanas também visa facilitar o intercâmbio de alunos de graduação, mestrado e doutorado, bem como a disponibilização de bolsas de estudo destinadas a custear a permanência de estudantes em universidades daquele país.

A estratégia de desenvolvimento de parcerias internacionais, centrada na Coreia do Sul, coloca a UNISINOS como a principal parceira brasileira das instituições daquele país, tanto em número de acordos de cooperação quanto em contingente de alunos e pesquisadores em processo de qualificação em universidades daquele país. Segundo um executivo da HT Micron: "Quando você começa a formar pessoal no exterior, [...] podem trabalhar em laboratórios fora e começar a desenvolver pesquisa. E, quando eles voltam, nossos laboratórios já estão prontos e podem continuar. É um processo". Ou seja, tanto o envio de pesquisadores e estudantes para a Coreia do Sul quanto a vinda de especialistas estrangeiros para UNISINOS surge como uma das estratégias de formação de recursos humanos mais importantes no universo do projeto.

Outra dimensão de relacionamento estratégico que a universidade vem desenvolvendo é com as esferas do poder público municipal, estadual e federal. A atração da empresa HT Micron e a implementação do itt CHIP foram viabilizados por meio de financiamentos, incentivos e políticas públicas dessas três esferas governamentais. No que se refere aos incentivos federais, o marco regulatório do PADIS foi fundamental, tanto para a construção e operação da planta produtiva, quanto para a viabilização de contratos de $\mathrm{P} \& \mathrm{D}$ junto à universidade.

As ações que a UNISINOS está empreendendo com vistas a ampliar sua colaboração com as demais organizações podem ser consideradas como práticas de desenvolvimento e fortalecimento das suas relações interorganizacionais, as quais têm incrementado a sua capacidade absortiva na área de encapsulamento de semicondutores. Portanto, a Proposição 4 da pesquisa também resultou em importantes reflexões no caso em estudo.

A Figura 3 representa um esquema geral das ações que a UNISINOS vem realizando para o desenvolvimento da sua capacidade absortiva no campo de encapsulamento de semicondutores, construído a partir das evidências empíricas da pesquisa.

$\mathrm{Na}$ Figura 3, os retângulos representam os quatro conjuntos de elementos da capacidade absortiva identificados na literatura, enquanto as elipses representam as ações implementadas pela UNISINOS para desenvolver essa capacidade na área de encapsulamento de semicondutores. O esquema ilustra visualmente que os quatro elementos (base de conhecimento; recursos humanos; estrutura organizacional; e relações interorganizacionais) foram trabalhados pela instituição como meios para desenvolver e aperfeiçoar a sua capacidade de absorção de conhecimentos externos numa área tecnológica específica.

Observa-se, no esquema apresentado, que muitas das ações desenvolvidas pela universidade podem influenciar mais de uma dimensão da capacidade absortiva. Um exemplo é o itt CHIP: mesmo que esteja relacionado diretamente à dimensão "estrutura organizacional", sua implementação apresenta forte influência no desenvolvimento de recursos humanos e no suporte de projetos colaborativos de P\&D. Outro exemplo é criação do Fórum Brasil-Coreia, que está associado à dimensão "estrutura organizacional", mas apresenta influência na dimensão de relações interorganizacionais, especialmente com instituições sul-coreanas.

\subsection{Implicações da pesquisa}

Quanto às implicações do desenvolvimento da capacidade absortiva da UNISINOS, é fundamental ressaltar a complexidade científico-tecnológica que permeia a área de semicondutores. Com relação a isso, os dados indicam uma decisão da universidade em fortalecer sua atuação na etapa tecnológica mais aplicada de toda a cadeia, o back-end. Mesmo apresentando uma significativa complexidade tecnológica, trata-se de uma das etapas relacionadas à produção final do componente, possibilitando à UNISINOS valer-se de toda uma capacidade técnico-científica já instalada em áreas afins. Os resultados encontrados neste estudo ratificam as evidências do trabalho de Lim 


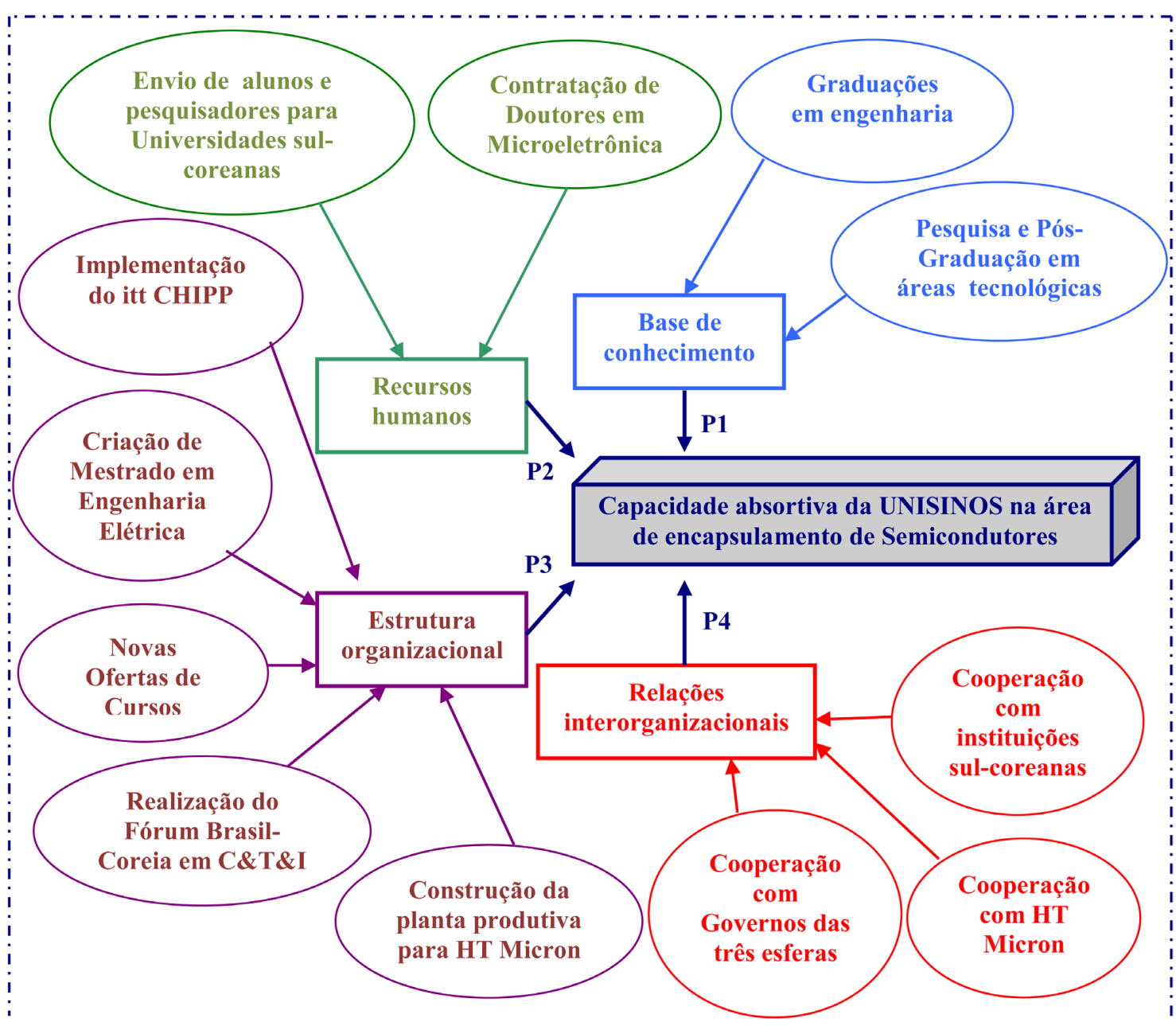

Figura 3. Ações de desenvolvimento da capacidade absortiva da UNISINOS. Fonte: Elaborada pelos autores.

(2009), o qual aponta que os conhecimentos dotados de maior aplicabilidade tecnológica tornam mais ágil o processo de construção da capacidade absortiva.

Não obstante, a atenção que as pesquisas voltadas para o encapsulamento têm recebido ultimamente e os refinamentos científicos daí decorrentes impõem desafios extras, tanto para a UNISINOS quanto para a HT Micron. Isso ocorre porque o conhecimento a ser adquirido e produzido será cada vez mais complexo, exigindo uma capacidade de absorção mais sofisticada e, portanto, mais dependente da trajetória de aprendizado da organização, conforme preconizam Cohen \& Levinthal $(1989,1990)$ e Zahra \& George (2002).

Quanto ao processo de desenvolvimento da capacidade absortiva da UNISINOS, de modo geral, tal processo mostrou-se bastante avançado, abrangendo uma série de ações estruturadas, as quais reforçam os quatro elementos da capacidade absortiva identificados na literatura relacionada. Nesse sentido, foram desenvolvidas inúmeras ações com o objetivo de: a) incrementar a base de conhecimento em encapsulamento de semicondutores, processo fundamental da capacidade absortiva, conforme sustentam Cohen \& Levinthal (1990), Daghfous (2004) e Murovec \& Prodan (2009); b) qualificar os recursos humanos especializados nessa área, conforme sustentam autores como Daghfous (2004) e Vinding (2006); c) aprimorar a estrutura organizacional relacionada ao projeto, conforme Cohen \& Levinthal (1990), Vega-Jurado et al. (2008); e d) fortalecer as relações interorganizacionais com importantes atores externos, conforme defendem Murovec \& Prodan (2009) e Lim (2009).

Também merece menção o horizonte temporal dessas ações. Algumas delas, como a contratação de especialistas e pesquisadores e o curso de formação em semicondutores, têm por objetivo suprir as carências imediatas da UNISINOS no tocante aos recursos humanos. Outras ações, como a implementação do itt CHIP, a criação e reestruturação de cursos de graduação, a criação do Mestrado Profissional na área 
e os acordos de cooperação internacional, apresentam uma perspectiva de longo prazo. Depreende-se, então, que a universidade está colocando em prática certas medidas destinadas a elevar sua capacidade de absorção de conhecimento sobre a área de encapsulamento de semicondutores.

\section{Considerações finais}

As quatro proposições apresentas na construção teórica encontraram evidências empíricas na pesquisa de campo, sendo fundamentais para o desenvolvimento da capacidade absortiva da UNISINOS na área de semicondutores as seguintes ações: a) a existência de base de conhecimento na universidade, representada pelos projetos de pesquisa desenvolvidos e pelos cursos afins à área de semicondutores; b) a qualificação de recursos humanos existentes e a contratação de novos pesquisadores; c) o desenvolvimento de infraestrutura científico-tecnológica na área de encapsulamento de semicondutores, destacando-se a implementação do itt CHIP, do mestrado profissional em engenharia elétrica, do fórum Brasil-Coreia, de novas ofertas de cursos, além da construção da planta fabril alugada para a HT Micron; d) o fortalecimento de relações interorganizacionais, especialmente com instituições de ciência e tecnologia sul-coreanas, com governos das três esferas e com a HT Micron.

Uma contribuição acadêmica dos resultados deste estudo é evidenciar que o desenvolvimento da capacidade absortiva não depende necessariamente da trajetória da organização, podendo, ao menos em parte, desenvolver-se no contexto de um empreendimento específico, o que agrega novas evidências a uma tendência recente nos estudos nesse campo de pesquisa. Essa é uma das principais contribuições para a literatura ao dar suporte a uma corrente alternativa defendida por $\operatorname{Lim}$ (2009) de que nem toda a capacidade absortiva é path dependente, o que contradiz boa parte da literatura, especialmente nos trabalhos clássicos de Cohen \& Levinthal (1990).

No que se relaciona ao dia a dia das organizações, uma contribuição desta pesquisa é a de auxiliar os gestores, de modo geral, e os profissionais que lidam com projetos tecnológicos, de modo particular, a identificar e selecionar iniciativas que podem incrementar a capacidade de absorção de conhecimentos externos em projetos específicos. Outra contribuição para o contexto organizacional é a própria apresentação do caso empírico analisado, o qual representa uma iniciativa idiossincrática entre universidade e empresa no desenvolvimento de empreendimentos tecnológicos, especificamente na área de semicondutores.

Outra reflexão propiciada pelos resultados está relacionada ao foco organizacional em que se apresentou a necessidade de desenvolvimento da capacidade absortiva. Em geral, na literatura, os projetos colaborativos entre universidade e empresa supõem que a necessidade de desenvolver a absorção do conhecimento esteja sempre na empresa. No entanto, com o nível de complexidade tecnológica que a sociedade vem experimentando, é importante que as universidades percebam que, em casos específicos, também precisam desenvolver ações para aumentar sua capacidade absortiva e ter maior êxito na transferência de conhecimento da indústria para a universidade.

Embora trate de temas recorrentes na literatura acadêmica, este trabalho pode vir a servir de base para outras pesquisas. Um exemplo seriam estudos destinados a entender como ocorre o desenvolvimento da capacidade absortiva por parte das empresas em projetos colaborativos dessa natureza, e explorar como as relações interorganizacionais afetam essa capacidade. Futuros estudos, também, poderão ser realizados para analisar como uma organização (p. ex. uma universidade) absorve conhecimentos de uma empresa e vice-versa, numa relação díade. E estudos teórico-empíricos poderão avançar na discussão sobre os elementos determinantes e os consequentes da capacidade de absorção de conhecimentos externos por universidades envolvidas em parcerias de cooperação em projetos estratégicos para o Brasil.

Para finalizar, cabe destacar que os resultados aqui apresentados devem ser relativizados, pois a pesquisa apresenta algumas limitações. A primeira está relacionada ao fato de que o objeto investigado, isto é, o desenvolvimento da capacidade de absorção de conhecimento da UNISINOS é um processo ainda em construção, sem ter os resultados definitivos. A segunda limitação diz respeito à natureza estratégica do projeto para ambas as instituições envolvidas, o que impõe determinadas restrições ao acesso de informações para um amplo entendimento da problemática pesquisada. Por fim, o estudo de caso concentrou-se na coleta de dados por meio de entrevistas em profundidade, não sendo utilizadas outras fontes, como a análise documental ou observação participante, o que poderia trazer outras evidências complementares para o estudo.

\section{Agradecimentos}

Agradecimentos ao CNPq e à FAPERGS pelo apoio financeiro para a pesquisa.

\section{Referências}

Ahuja, G. (2000). The duality of collaboration: inducements and opportunities in the formation of interfirm linkages. Strategic Management Journal, 21(3), 317-343. http://dx.doi. org/10.1002/(SICI)1097-0266(200003)21:3<317::AIDSMJ90>3.0.CO;2-B.

Balestrin, A., Vargas, L. M., \& Fayard, P. (2008). Knowledge creation in small-firm network. Journal of Knowledge Management, 12(2), 94-106. http://dx.doi. org/10.1108/13673270810859541. 
Baum, J. A. C., Calabrese, T., \& Silverman, B. S. (2000). Don't go it alone: alliance network composition and startups' performance in Canadian biotechnology. Strategic Management Journal, 21(3), 267-294. http:/dx.doi. org/10.1002/(SICI)1097-0266(200003)21:3<267::AIDSMJ89>3.0.CO;2-8.

Benbasat, I., Goldstein, D., \& Mead, M. (1987). The case research strategy in studies of information systems. Management Information Systems Quarterly, 11(3), 369-386. http://dx.doi.org/10.2307/248684.

Bettenhausen, K., \& Murnighan, J. K. (1986). The emergence of norms in competitive decision-making groups. Administrative Science Quarterly, 30, 350-372.

Camisón, C., \& Fores, B. (2010). Knowledge absorptive capacity: new insights for its conceptualization and measurement. Journal of Business Research, 63(7), 707-715. http://dx.doi.org/10.1016/j.jbusres.2009.04.022.

Chang, Y. C. (2003). Benefits of cooperation on innovative performance: evidence from integrated circuits and biotechnology firms in the UK and Taiwan. $R$ \& D Management, 33(4), 425-437. http://dx.doi. org/10.1111/1467-9310.00308.

Cohen, W. M., \& Levinthal, D. A. A. (1989). Innovation and learning: the two faces of R\&D. The Economic Journal, 99(397), 569-596. http://dx.doi.org/10.2307/2233763.

Cohen, W. M., \& Levinthal, D. A. A. (1990). Absorptive capacity: a new perspective on learning and innovation. Administrative Science Quarterly, 35(1), 128-152. http:// dx.doi.org/10.2307/2393553.

Daghfous, A. (2004). Absorptive capacity and the implementation of knowledge-intensive best practices. S.A.M. Advanced Management Journal, 69(2), 17-21.

Eisenhardt, K. M. (1989). Building theories from case study research. Academy of Management Review, 14(4), 532-550.

George, G., Zahra, S. A., Wheatley, K. K., \& Khan, R. (2001). The effects of aliance portfolio characteristics and absorptive capacity on performance: a study of biotechnology firms. The Journal of High Technology Management Research, 12(2), 205-226. http://dx.doi. org/10.1016/S1047-8310(01)00037-2.

Gersick, C. (1988). Time and transition in work teams: toward a new model of group development. Academy of Management Journal, 31, 9-41.

Hagedoorn, J., \& Duysters, G. (2002). The effect of mergers and acquisitions on the technological performance of companies in a high-tech environment. Technology Analysis and Strategic Management, 14(1), 67-85. http://dx.doi.org/10.1080/09537320220125892.

Keil, T., Maula, M., Schildt, H., \& Zahra, S. A. (2008). The effect of governance modes and relatedness of external business development activities on innovative performance. Strategic Management Journal, 29(8), 895-907. http://dx.doi.org/10.1002/smj.672.

Lane, P. J., \& Lubatkin, M. (1998). Relative absorptive capacity and interorganizational learning. Strategic Management Journal, 19(5), 461-477. http://dx.doi. org/10.1002/(SICI)1097-0266(199805)19:5<461::AIDSMJ953>3.0.CO;2-L.

Lane, P. J., Koka, B. R., \& Pathak, S. (2006). The reification of absorptive capacity: a critical review and rejuvenation of the construct. Academy of Management Review, 31(4), 833-863. http://dx.doi.org/10.5465/AMR.2006.22527456.

Laursen, K., Leone, M. I., \& Torrisi, S. (2010). Technological exploration through licensing: new insights from the licensee's point of view. Industrial and Corporate Change, 19(3), 871-897. http://dx.doi.org/10.1093/icc/dtq034.

Lim, K. (2009). The many faces of absorptive capacity: spillovers of copper interconnect technology for semiconductor chips. Industrial and Corporate Change, 18(6), 1249-1284. http://dx.doi.org/10.1093/icc/dtp044.

Lin, C., Wu, Y., Chang, C., Wang, W., \& Lee, C. (2012). The alliance innovation performance of R\&D alliances: the absorptive capacity perspective. Technovation, 32(5), 282292. http://dx.doi.org/10.1016/j.technovation.2012.01.004.

Müller-Seitz, G., \& Güttel, W. (2013). Toward a choreography of congregating: a practice-based perspective on organizational absorptive capacity in a semiconductor industry consortium. Management Learning, 45(4), 477-497. http://dx.doi.org/10.1177/1350507613497323.

Murovec, N., \& Prodan, I. (2009). Absorptive capacity, its determinants and influence on innovation output: cross-cultural validation of the structural model. Technovation, 29(12), 859-872. http://dx.doi.org/10.1016/j. technovation.2009.05.010.

Ripper, J. E., Fo. (2004). História da microeletrônica no Brasil. In Brasil. Ministério do Desenvolvimento, Indústria e Comércio Exterior. O futuro da indústria de semicondutores: a perspectiva do Brasil. Coletânea de artigos (p. 19-31). Brasília: Instituto Evaldo Lodi/ Núcleo Central.

Schmidt, T. (2010). Absorptive capacity: one size fits all? A firm-level analysis of absorptive capacity for different kinds of knowledge. Managerial and Decisions Economics, (31), 1-18.

Vega-Jurado, J., Gutiérrez-Gracia, A., \& Fernandez-DeLucio, I. (2008). Analyzing the determinants of firm's absorptive capacity: beyond R\&D. $R \&$ D Management, 38(4), 392-405. http://dx.doi.org/10.1111/j.14679310.2008.00525.x.

Veugelers, R. (1998). Collaboration in R\&D: an assessment of theoretical and empirical findings. De Economist, 146(3), 419-443. http://dx.doi.org/10.1023/A:1003243727470.

Vinding, A. L. (2006). Absorptive capacity and innovative performance: a human capital approach. Economics 
of Innovation and New Technology, 15(4-5), 507-517. http://dx.doi.org/10.1080/10438590500513057.

Wacheux, F. (1996). Méthodes qualitatives et recherche en gestion. Paris: Economica.

Xia, T., \& Roper, S. (2008). From capability to connectivityAbsorptive capacity and exploratory alliances in biopharmaceutical firms: a US-Europe comparison.
Technovation, 28(11), 776-785. http://dx.doi.org/10.1016/j. technovation.2008.03.007.

Yin, R. K. (1994). Case study research: design and methods (2nd ed.). California: Sage Publications.

Zahra, S. A., \& George, G. (2002). Absorptive capacity: a review, reconceptualization, and extension. Academy of Management Review, (27), 185-203. 